
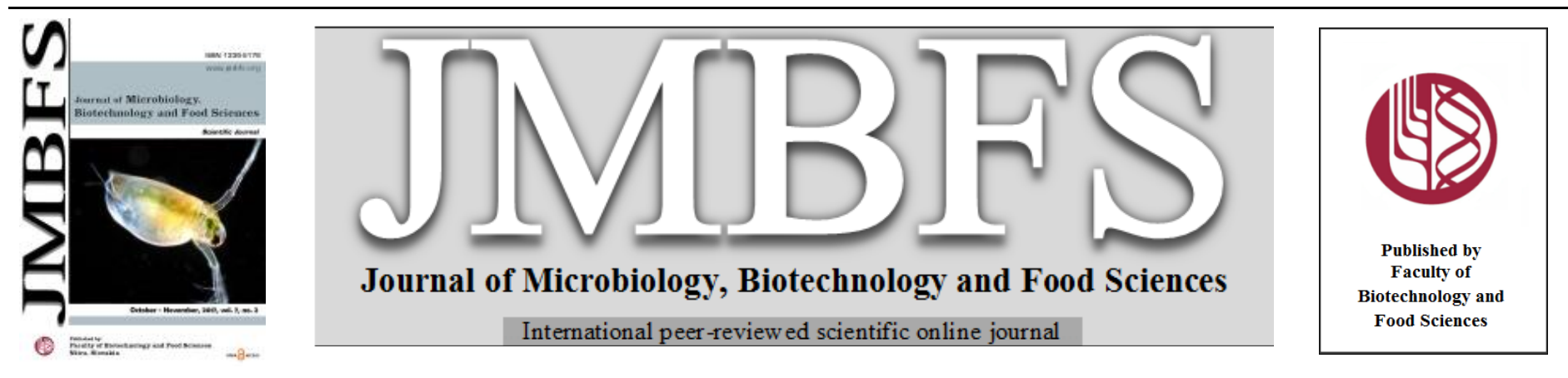

\title{
DETECTION OF MYCOTOXINS USING MALDI-TOF MASS SPECTROMETRY
}

\section{Lukáš Hleba $^{1}$, Miroslava Císarová ${ }^{2}$, Mohammad Ali Shariati ${ }^{3}$, Dana Tančinovál ${ }^{1}$}

Address(es): Ing. Lukáš Hleba, Ph.D.

${ }^{1}$ Slovak University of Agriculture in Nitra, Faculty of Biotechnology and Food Sciences, Department of Microbiology, Tr. Andreja Hlinku 1, 94976 Nitra, Slovak Republic.

${ }^{2}$ Department of Biology, Faculty of Natural Sciences, University of SS. Cyril and Methodius, Nám. J. Herdu 2, Trnava, Slovakia.

${ }^{3}$ Senior Researcher, Department of Scientific affairs, Kurks State Agricultural Academy, Kurks, Russia \& Researcher, All-Russian Research Institute of

Phytopathology of the Federal Agency of Scientific Organizations of Russia, Moscow, Russia. Tel: +7(495)597-42-28.

*Corresponding author: lukas.hleba@uniag.sk

doi: 10.15414/jmbfs.2017.7.2.181-185

\section{ARTICLE INFO}

Received 9. 11. 2016

Revised 15. 3. 2017

Accepted 5. 9. 2017

Published 1. 10. 2017

\section{Regular article}

OPEN $\partial_{\text {ACCESS }}$

\section{ABSTRACT}

Mycotoxins are toxic substances produced by some microscopic fungi such as Aspergillus, Fusarium and Penicillium sp. These species commonly contaminate foods and feeds. Therefore, the quick and accurate detection is very necessary. In this study, a six mycotoxins, concretely: aflatoxin $\mathrm{B}_{1}$, citrinin, deoxynivalenol, zearalenone, T2-toxin, and griseofulvin were detected by Matrix Assisted Laser Desorption/Ionization Time-of-flight Mass Spectrometry (MALDI-TOF MS). In addition, sodium adducts were observed in all tested mycotoxins. All mycotoxins were ionizated by HCCA matrix. Our results showed that it is possible to detect selected mycotoxins by MALDI-TOF MS Microflex LT in linear positive ion mode.

Keywords: Mycotoxins, Maldi TOF MS, detection

\section{INTRODUCTION}

Mycotoxins are toxic metabolites produced by fungal species that commonly contaminate staple foods and feeds. They represent an unavoidable problem due to their presence in globally consumed cereals such as rice, maize and wheat (Marroquín-Cardona et al., 2014). Furthermore, these compounds have a great financial impact. From an economic point of view, mycotoxins cause money loss to producers, processors and also consumers of food and feed (Bryden, 2012; Oliveira and Catharino, 2014). Mycotoxins are thermally stable and demonstrate high levels of bioaccumulation. They are approximately 300-700 Da long and their production is genotypically specific, but is not limited to one species, or one toxin per species (Turner et al., 2015). Mycotoxins have been more closely monitored in the past decades due to their harsh effects observed in humans and animals; potent toxic effects in humans and animals have been related to these molecules, such as cytotoxicity, carcinogenicity, mutagenicity, neurotoxicity, hepatotoxicity, immunosuppressive, and estrogenic effects (Ayedboussema et al., 2008; Belli et al., 2010). Reproductive alterations in animals were induced by mycotoxin addition (Medvedova et al., 2011; Kolesarova $\boldsymbol{e}$ al., 2012; Maruniakova et al., 2012, 2014, 2015; Halenar et al., 2015). The main group of moulds and mycotoxins of world - wide concern are Aspergillus spp. (producing aflatoxins B1, B2,G1,G2,OTA and patulin), Fusarium spp. (producing T-2 toxin, deoxynivalenol, zearalenone and fumonisin B1) and Penicillium spp. (producing OTA) (Zain, 2011). The International Agency for Cancer Research (IARC) has classified a number of mycotoxins formally as agents that are proven (Group 1 - AF B1, AF B2, AF G1 and AF G2), probably (Group 2A), and possibly (Group 2B OTA) carcinogenic to humans. With a wide-ranging structural diversity of mycotoxins, severe toxic effects caused by these molecules and their high chemical stability the requirement for robust and effective detection methods is clear (Bhat et al., 2010; IARC, 2015). Mycotoxin toxicity in foodstuff can occur at very low concentrations necessitating early availability of sensitive and reliable methods for their detection. Conventional analytical methods for mycotoxin detection include thin-layer chromatography (TLC), high-performance liquid chromatography (HPLC) coupled with ultraviolet (UV), diode array (DAD), fluorescence (FD) or mass spectrometry (MS) detectors, gas chromatography (GC) coupled with electron capture (ECD), flame ionization (FID) or MS detectors (Chauhan $\boldsymbol{e t}$ al., 2016) and enzymelinked immunoassay (ELISA) (Wang et al., 2011). Though these methods are well known for their accurate and precise detection of mycotoxin in food or feed samples, they require skilled operators, extensive sample pre-treatment, equipment and may lack accuracy at low analyte concentration and very often the using of classical method is expensive processes (Cigić and Prosen, 2009; Goryacheva et al., 2007; Blechova et al., 2006). Therefore, a rapid, sensitive and specific assay technique is required for the routine analysis of foods, and beverages (Chauhan et al., 2016). Matrix-assisted laser desorption ionization time of flight mass spectrometry (MALDI-TOF MS) instrumentation enables highly sensitive and fast analysis and/or detection using a very small sample (Blechova et al., 2006). The Matrix-assisted laser/desorption ionization time of flight mass spectrometry (MALDI-TOF MS) instrumentation is a rather new technique developed two decades ago (Tanaka et al., 1988). It enables highly sensitive and rapid analysis at femtomole or even attomole levels of organic and/or high molecular biomolecules without their destruction. Another advantage of MALDI-TOF MS over conventional techniques is its ability to analyse samples within a few minutes and using an only small sample. Thus, the MALDI-TOF MS method could offer the possibility for fast and sensitive detection of mycotoxins (Elosta et al., 2007).

Therefore, the aim of this study was the detection of selected pure mycotoxins by MALDI-TOF Mass Spectrometry.

\section{MATERIAL AND METHODS}

\section{Mycotoxins}

A six different type of mycotoxins, aflatoxin $\mathrm{B} 1\left(\mathrm{C}_{17} \mathrm{H}_{12} \mathrm{O}_{7}=328.27 \mathrm{Da}\right)$, citrinin $\left(\mathrm{C}_{13} \mathrm{H}_{14} \mathrm{O}_{5}=250.25 \mathrm{Da}\right)$, deoxynivalenol $\left(\mathrm{C}_{15} \mathrm{H}_{20} \mathrm{O}_{6}=296.32 \mathrm{Da}\right)$, zearalenone $\left(\mathrm{C}_{18} \mathrm{H}_{22} \mathrm{O}_{5}=318.36 \mathrm{Da}\right)$, T2-toxin $\left(\mathrm{C}_{24} \mathrm{H}_{34} \mathrm{O}_{9}=466.52 \mathrm{Da}\right)$, and griseofulvin $\left(\mathrm{C}_{17} \mathrm{H}_{17} \mathrm{ClO}_{6}=352.77 \mathrm{Da}\right)$ were used in this study. All mycotoxins were obtained from Sigma Aldrich, Germany.

\section{Preparing of mycotoxins for MALDI-TOF MS}

All mycotoxins were dissolved in methanol at concentration $0.1 \mathrm{mg} / \mathrm{mL}$. A $1 \mu$ of mycotoxin solution was replaced by pipetting onto the 96 targets stainless steel plate (Bruker daltonics, Germany). Every second repetition of the sample was mixed with $10 \mathrm{M} \mathrm{NaCl}$ solution. After drying, a $1 \mu 1$ of HCCA ( $\alpha$-cyano-4hydroxycinnamic acid) dissolved in the solution contained $50 \%$ acetonitrile, 47.5 $\%$ water and $2.5 \%$ trifluoracetic acid. This matrix was dried at room temperature. 


\section{MALDI-TOF MS mycotoxin detection}

After drying, each spectrum was collected by MALDI-TOF MS LT Microflex (Bruker Daltonics, Germany) operating in linear positive mode with following set using flexControl software (Bruker Daltonics, Germany): laser frequency: $60 \mathrm{~Hz}$ laser attenuator: 20-30 \%, gain detector: 1.0x, spectrum range: 100-700 Da, ion source 1: $18 \mathrm{kV}$, ion source 2: $15 \mathrm{kV}$, lens: $6 \mathrm{kV}$, pulsed ion extraction: $0 \mathrm{~ns}$ Spectra were measured randomly by 500 laser shots. As calibrant HCCA matrix was used.

\section{Spectra analysis}

Obtained spectra were observed by flexAnalysis 3.4 software (Bruker Daltonics, Germany). Detection of peaks were done by centroid detection algorithm with a signal-to-noise threshold of 1 , a relative intensity threshold of $0 \%$, a minimum intensity threshold of 0 , a peak width of $0.2 \mathrm{~m} / \mathrm{z}$, a height of $80 \%$, a Tophat baseline subtraction, without smoothing algorithm, a width of $0.2 \mathrm{~m} / \mathrm{z}$, and cycle of 1 . Theoretical peaks of mycotoxins was compared with our detected mass with $\mathrm{a} \pm 0.5 \mathrm{~m} / \mathrm{z}$

\section{RESULTS AND DISCUSSION}

\section{Mycotoxins detection}

Food and feed may be contaminated by a variety of mycotoxins produced by microscopic filamentous fungi. Therefore, it is necessary to detect these mycotoxins. However, some of the methods actually used for detection of mycotoxins are rely on sample preparation based on volatile organic solvents, often comprising complex multi-step procedures and devoid of clean-up and concentration effects. Here, we used a simple preparation methodology for detection of mycotoxins that offers the advantages of short analysis time and low sample consumption.

Detection of aflatoxin B1 was tested with HCCA matrix. Aflatoxin B1 spectrum was observed between $300-350 \mathrm{~m} / \mathrm{z}$. The peaks were identified as $[\mathrm{M}+\mathrm{H}]^{+}$ 313.109 and $[\mathrm{M}+\mathrm{Na}]^{+}$at 335.059 Da. Peaks in repetition sample with $\mathrm{NaCl}$ solution were detected in the same position. Spectrum resolution and purity in higher quality was found in the sample with the addition of $\mathrm{NaCl}$ solution but the intensity was lower than sample without $\mathrm{NaCl}$ solution. Aflatoxin $\mathrm{B} 1$ spectrum obtained by MALDI-TOF MS is presented in figure 1.

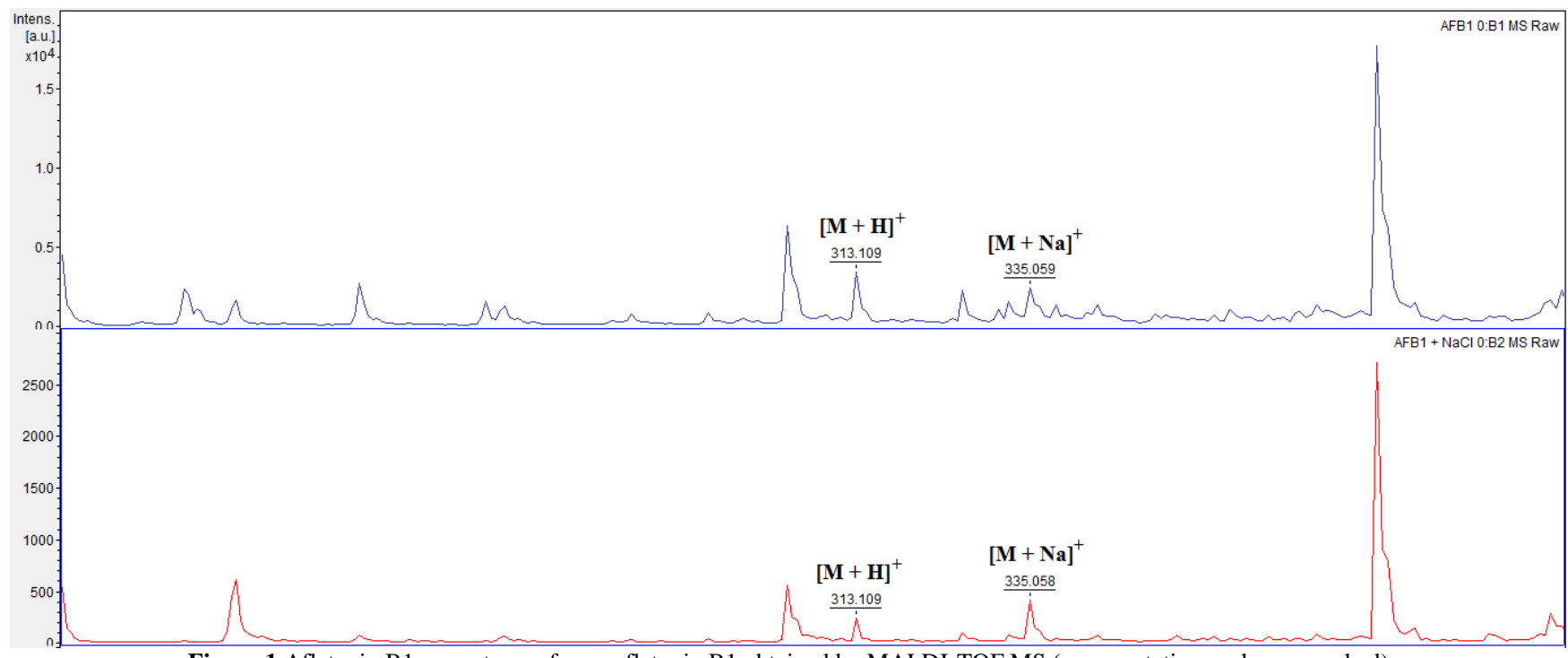

Figure 1 Aflatoxin B1 - spectrum of pure aflatoxin B1 obtained by MALDI-TOF MS (representative peaks are marked)

Authors Catharino et al., 2005 studied aflatoxins by MALDI-TOF MS in reflectron positive ion modes with using the same matrix (HCCA) with addition of $10 \mathrm{mM} \mathrm{NaCl}$ and they detected aflatoxin $\mathrm{B} 1$ as $[\mathrm{M}+\mathrm{Na}]^{+}$at $335 \mathrm{Da}$. In our study we determined that it's possible to detect protonated pure aflatoxin B1 as $[\mathrm{M}+\mathrm{H}]^{+}$at 313 Da. Also Farzaneh et al., 2012 used ESI triple-quadrupole mass spectrometer for detection of aflatoxin B1 and they identified three peaks in aflatoxin B1 spectrum. Spectrum contains following peaks: $[\mathrm{M}+\mathrm{H}]^{+}$at $313 \mathrm{Da}$
$[\mathrm{M}+\mathrm{Na}]^{+}$at $335 \mathrm{Da}$ and $[2 \mathrm{M}+\mathrm{Na}]^{+}$at $647 \mathrm{Da}$. In our study peak $[2 \mathrm{M}+\mathrm{H}]^{+} \operatorname{did}$ not detect.

Citrinin spectrum was found as five different peaks. Spectrum was obtained using the same matrix (HCCA) and peaks were identified as $\left[\mathrm{M}-\mathrm{H}_{2} \mathrm{O}-\mathrm{CO}\right]^{+}$at 205.383 $\mathrm{Da},\left[\mathrm{M}-\mathrm{H}_{2} \mathrm{O}\right]^{+}$at $234.393 \mathrm{Da},[\mathrm{M}+\mathrm{H}]^{+}$at $251.359 \mathrm{Da},[\mathrm{M}+\mathrm{Na}]^{+}$at $273.218 \mathrm{Da}$ and $[\mathrm{M}+\mathrm{K}]^{+}$at $289.455 \mathrm{Da}$. Spectrum with addition of $\mathrm{NaCl}$ solution was found at the same position. Identified spectrum has the same resolution, purity, and intensity into the both cases. Citrinin spectrum is showed in figure 2 .

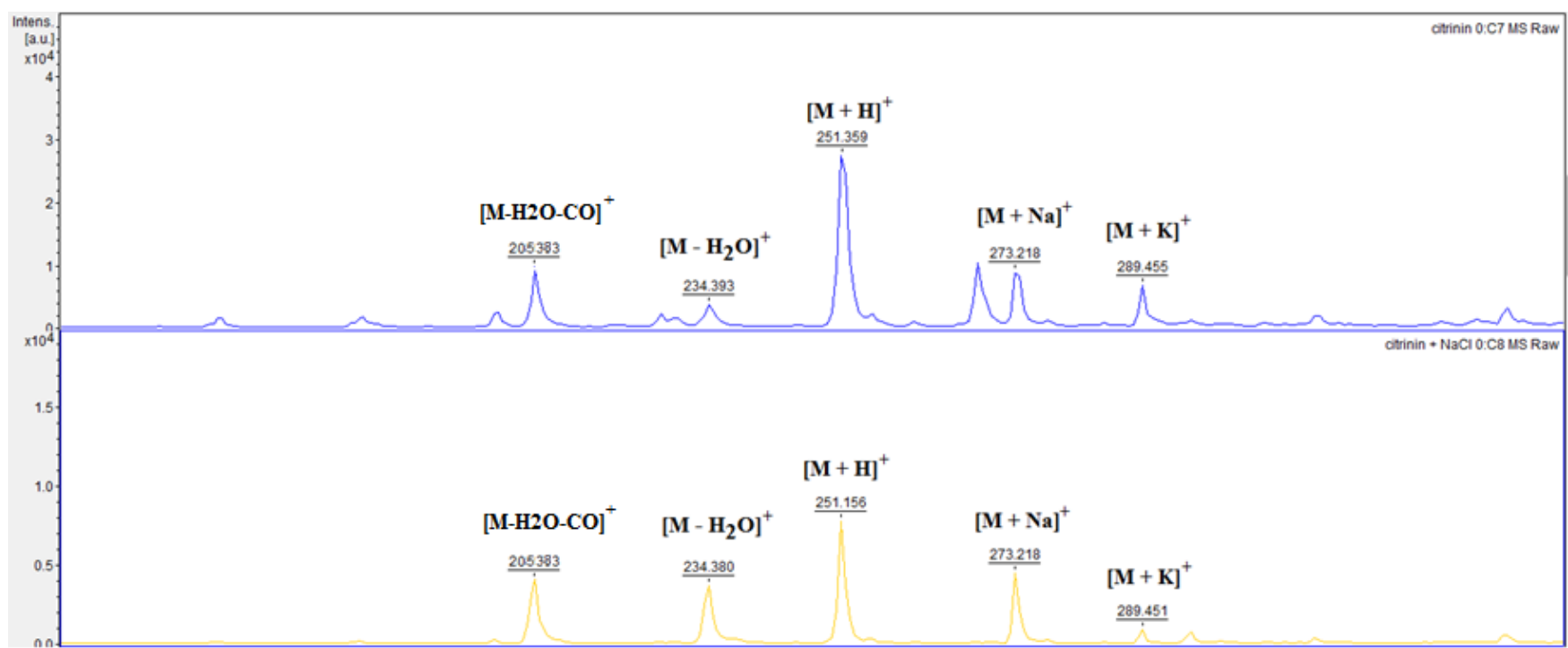

Figure 2 Citrinin - spectrum of pure citrinin obtained by MALDI-TOF MS (representative peaks are marked)

Citrinin was detected by Blanc et al., 1995 using tandem 6F LSIMS (Liquid Secondary Ionization Mass Spectrometry). The main peak was detected as $[\mathrm{M}+\mathrm{H}]+$ at $251 \mathrm{Da}$. Expect this one, other adducts were detected as $[\mathrm{M}+\mathrm{Na}]^{+}$at
$273 \mathrm{Da},[\mathrm{M}+\mathrm{K}]^{+}$at $289 \mathrm{Da}$ and fragment with water loss $\left[\mathrm{M}-\mathrm{H}_{2} \mathrm{O}\right]^{+}$at $233 \mathrm{Da}$. On the other hand, Li et al., 2012 used LC-ESI-MS/MS for citrinin detection and they found also fragment with water and carbon oxid loss $\left[\mathrm{M}-\mathrm{H}_{2} \mathrm{O}-\mathrm{CO}\right]^{+}$. Our 
study, where the Microflex LT in linear positive ion modes was used, showed the same results.

Deoxynivalenol spectrum was found as three peaks. In comparing with theoretical peaks of deoxynivalenol were found at the same position Deoxynivalenol contain following peaks: $[\mathrm{M}+\mathrm{H}]^{+}$at $296.207 \mathrm{Da},[\mathrm{M}+\mathrm{Na}]^{+}$at
319.486 Da and $[\mathrm{M}+\mathrm{K}]^{+}$at $335.764 \mathrm{Da}$. The intensity of identified peaks was higher in without addition of $\mathrm{NaCl}$ solution to sample and purity and resolution were at the same level into the both cases. Spectrum for deoxynivalenol obtained by MALDI-TOF MS is presented in figure 3.

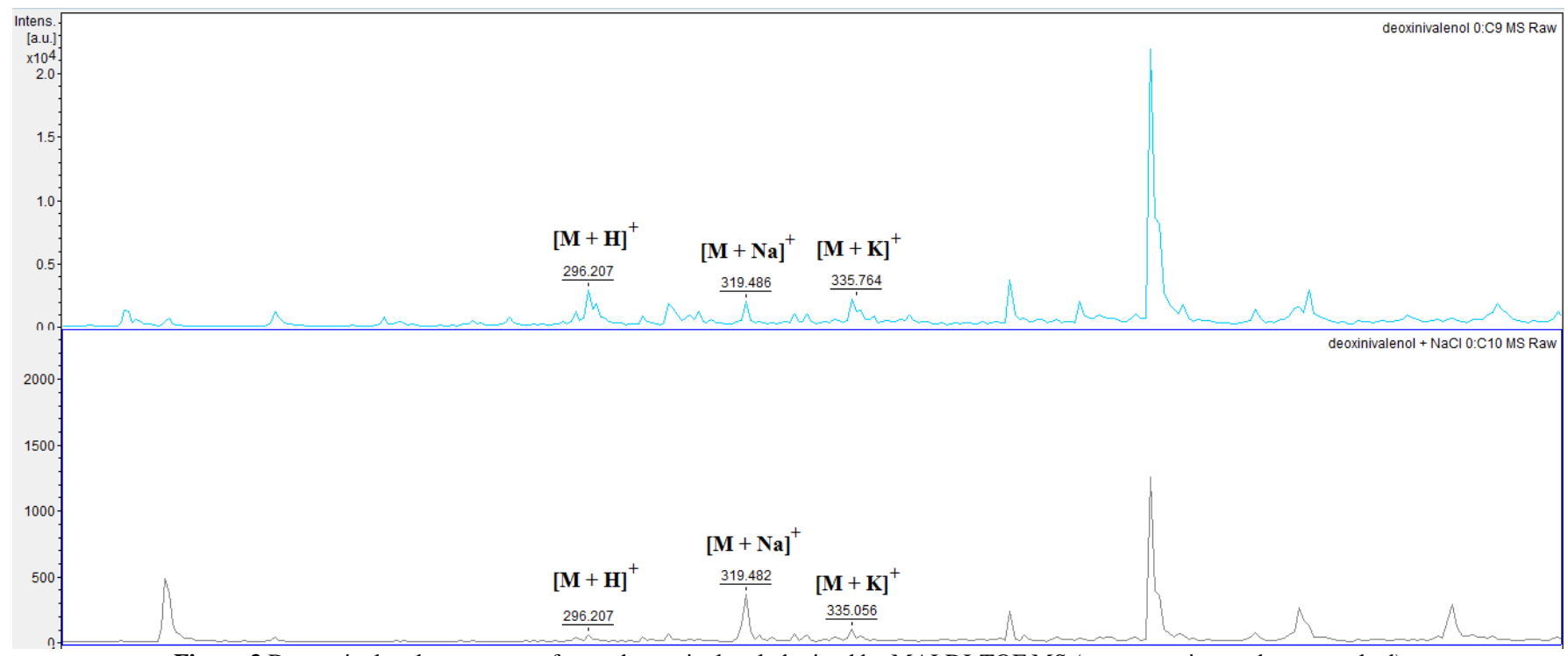

Figure 3 Deoxynivalenol - spectrum of pure deoxynivalenol obtained by MALDI-TOF MS (representative peaks are marked)

Blechova et al., 2006 used Axima-CFR instrument, which uses laser with 337 $\mathrm{nm}$ and reflectron linear positive mode was used. They detected typical peaks for deoxynivalenol as $[\mathrm{M}+\mathrm{Na}]^{+}$at $319.11 \mathrm{Da}$ and $[\mathrm{M}+\mathrm{K}]^{+}$at $335.09 \mathrm{Da}$. Expect these adducts, results from our study showed the peak of pure deoxynivalenol as $[\mathrm{M}+\mathrm{H}]+$ at 295.207 Da. Other authors, Berthiller et al., 2009 detected deoxynivalenol using $\mathrm{LC}-\mathrm{MS} / \mathrm{MS}$ as acetate adduct $\left[\mathrm{M}+\mathrm{CH}_{3} \mathrm{COO}\right]^{-}$at $355.1 \mathrm{Da}$.
Zearalenone spectrum was found as complex of three peaks into the both samples. The both spectrum showed the same position, purity and resolution of peaks. The sample where $\mathrm{NaCl}$ was added showed the lower intensity as without solution. The peaks were identified as $\left[\mathrm{M}-\mathrm{H}_{2} \mathrm{O}\right]^{+}$at $301.165 \mathrm{Da},[\mathrm{M}+\mathrm{H}]^{+}$at 319.483 $\mathrm{Da}$ and $[\mathrm{M}+\mathrm{Na}]^{+}$at $341.648 \mathrm{Da}$. Zearalenone spectrum is presented in figure 4.

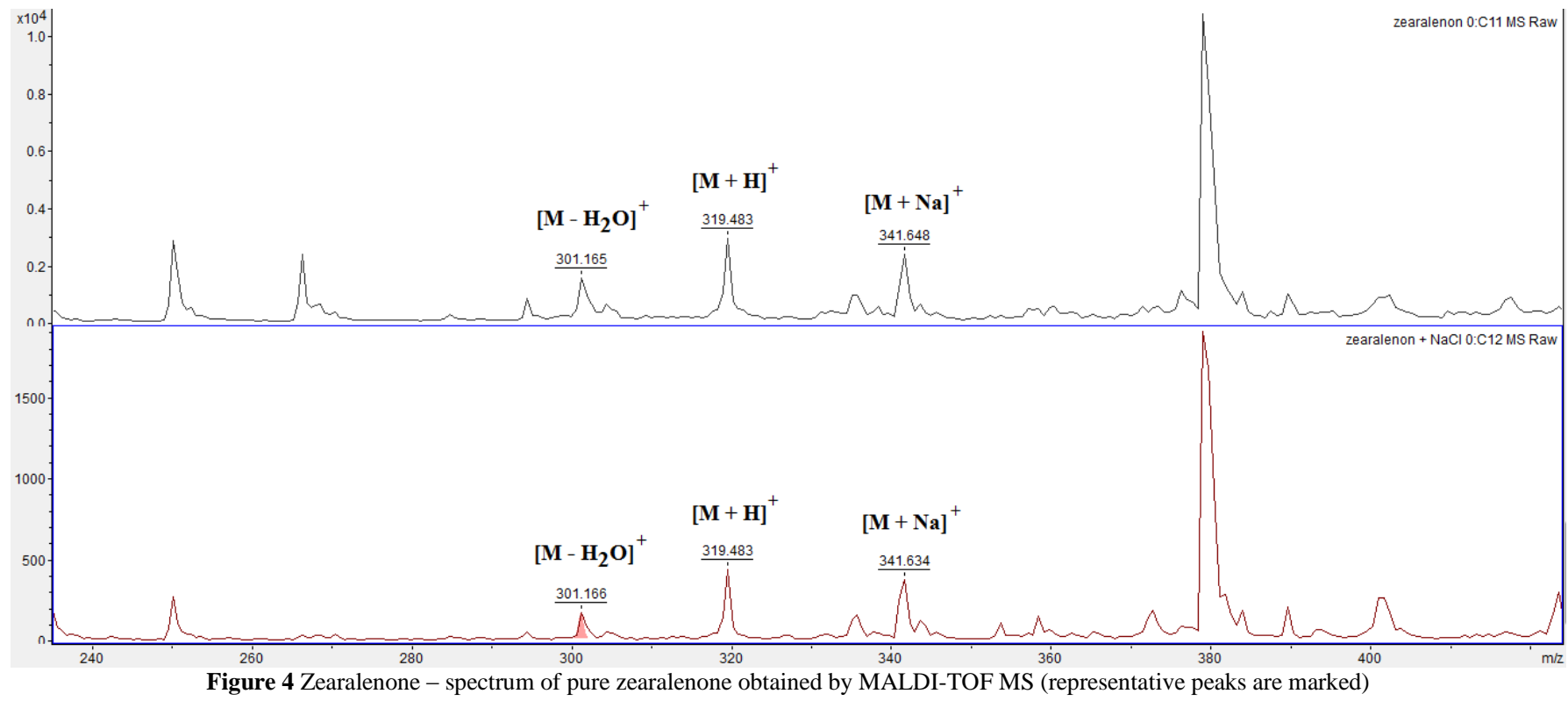

Engelhardt et al., 1988 researched transformation of the Fusarium mycotoxin zearalenone in maize cell suspension cultures using DCI-mass spectrometry after TLC and HPLC purification and they detected zearalenone as $[\mathrm{M}+\mathrm{H}]^{+}$at $319 \mathrm{Da}$. The intensity of spectrum for T2-toxin was found on the same level into the both samples. Resolution and purity of peaks too. The pure zearalenone spectrum was found as two peaks. Peak with 489.501 $\mathrm{Da}$ was identified as $[\mathrm{M}+\mathrm{Na}]^{+}$and peak with $505.487 \mathrm{Da}$ as $[\mathrm{M}+\mathrm{K}]^{+}$. The protonated peak of pure zearalenone $[\mathrm{M}+\mathrm{H}]^{+}$ was not found. In the case of $\mathrm{NaCl}$ solution one peak with $489.511 \mathrm{Da}$ was identified as $[\mathrm{M}+\mathrm{Na}]^{+}$. Other peaks were not found. T2-toxin spectrum obtained by MALDI-TOF MS is showed in figure 5 . 


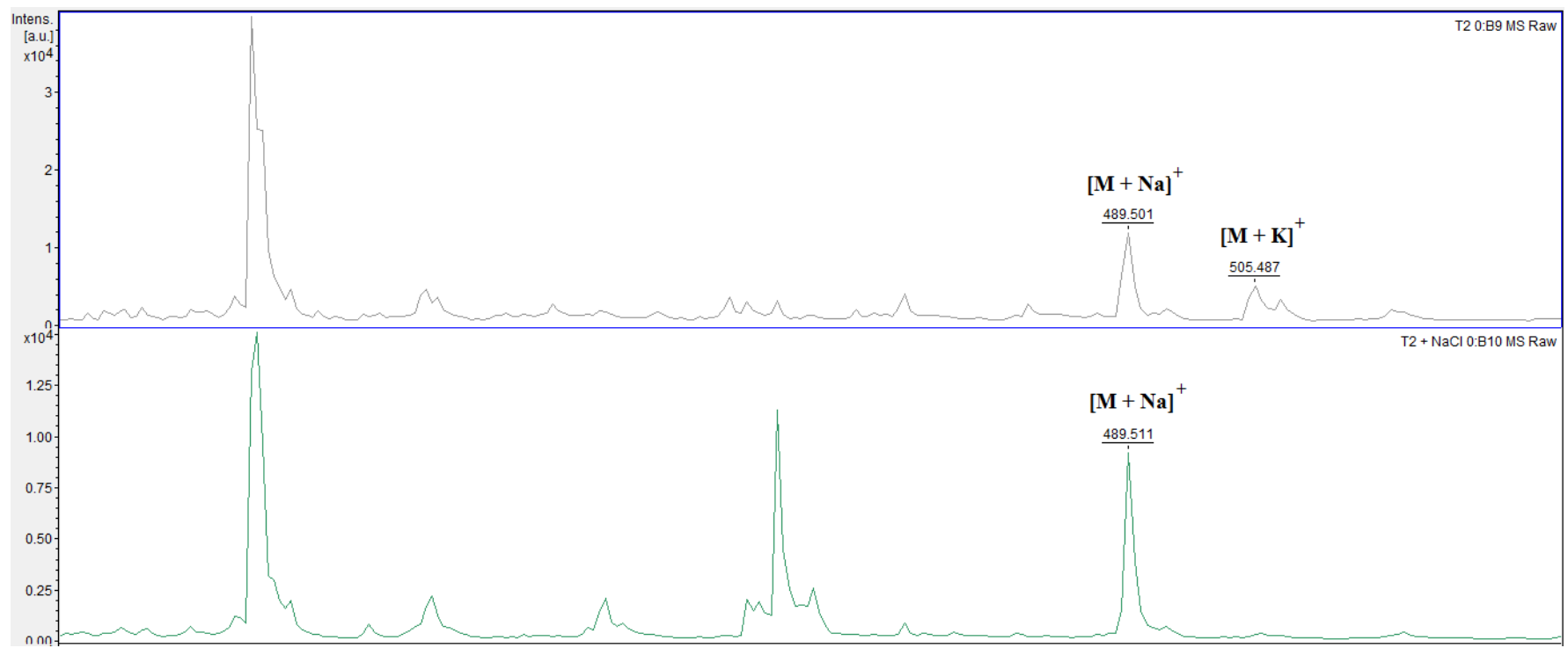

Figure 5 T2 toxin - spectrum of pure T2-toxin obtained by MALDI-TOF MS (representative peaks are marked)

T2-toxin-d3was detected by Binder et al., 2007 using HPLC as spectrum of two peaks: $487 \mathrm{Da}$ and $492 \mathrm{Da}$.

Griseofulvin was identified as two peaks with following positions and peaks: $[\mathrm{M}+\mathrm{H}]^{+}$at $353.023 \mathrm{Da}$ and $[\mathrm{M}+\mathrm{Na}]^{+}$at $375.613 \mathrm{Da}$. Peaks was found in high quality of resolution and purity in the both samples, expect intensity. Intensity was higher in the sample without $\mathrm{NaCl}$ solution. Second peak $[\mathrm{M}+\mathrm{Na}]^{+}$with 375.613 Da can be difficult to detect because it has very close to the matrix $[2 \mathrm{M}+\mathrm{H}]^{+}$with $379 \mathrm{Da}$. Griseofulvin spectrum is presented in figure 6

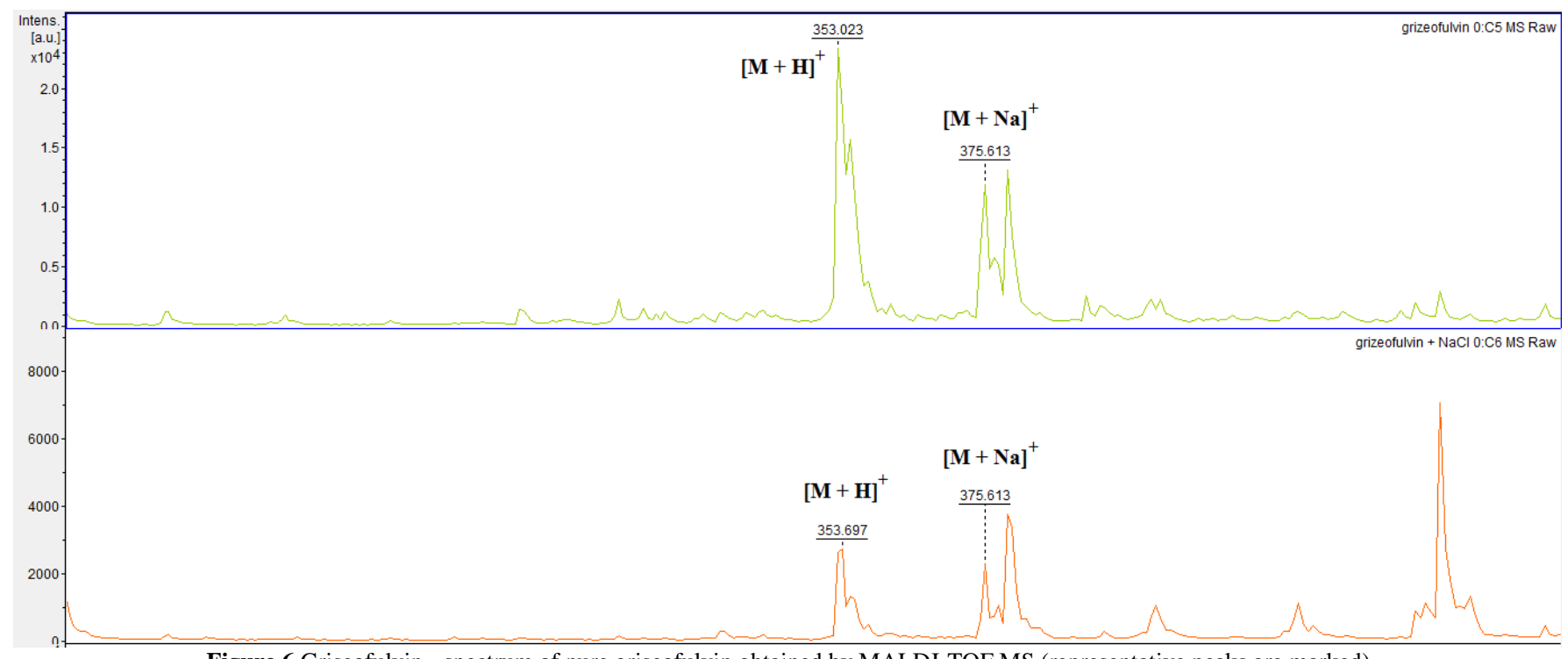

Figure 6 Griseofulvin - spectrum of pure griseofulvin obtained by MALDI-TOF MS (representative peaks are marked)

In study of Petit et al., 2004 was used ESI-IT Mass Spectrometry for griseofulvin detection. They detected griseofulvin as $[\mathrm{M}+\mathrm{H}]+$ at 353 Da. Authors Rundberget and Wilkins, 2002 determinated some types of mycotoxins, produced by Penicillium spp., including the griseofulvin in food and feeds using LC-MS and LC-MS-MS. They obtained griseofulvin as $[\mathrm{M}+\mathrm{H}]+$ at $355 \mathrm{Da}$.

\section{CONCLUSION}

Presented data showed that it is possible to detect mycotoxins with using MALDI-TOF Mass Spectrometer Microflex LT operating in linear ion positive mode in very short time. The methodology is very fast and cheap, and it can be used for various mycotoxins which is produced by microscopic fungi. This analytical method is useful and powerful tool for qualitative identification different kind of small organic molecules such as mycotoxins.

Acknowledgement: This work has been supported by grant APVV-0304-12 and European Community under project no. 26220220180: Building Research Centre „AgroBioTech".

\section{REFERENCES}

Ayed-boussema, I., Bouaziz, C., Rjiba, K., Valenti, K., Laporte, F. (2008). The mycotoxin Zearalenone induces apoptosis in human hepatocytes ( HepG2 ) via p53-dependent mitochondrial signaling pathway, Toxicology in Vitro 22, 16711680. https://doi.org/10.1016/i.tiv.2008.06.016

Belli, P., Bellaton, C., Durand, J., Balleydier, S., Milhau, N., Mure, M., Mornex, J., Benahmed, M., Le, C., Anatomopathologie, S., Nationale, E., Lyon, V. De
Etoile, M. (2010). Fetal and neonatal exposure to the mycotoxin zearalenone induces phenotypic alterations in adult rat mammary gland. Food Chem. Toxicol., 48, 2818-2826. https://doi.org/10.1016/j.fct.2010.07.012

Berthiller, F., Dall'Asta, C., Corradini, R., Marchelli, R., Sulyok, M., Krska, R., $\ldots$ \& Schuhmacher, R. (2009). Occurrence of deoxynivalenol and its 3- $\beta$-D glucoside in wheat and maize. Food Additives and Contaminants, 26(4), 507-511. https://doi.org/10.1080/02652030802555668

Bhat, R., Rai, R. V, Karim, A.A. (2010). Mycotoxins in Food and Feed : Presen Status and Future Concerns, 9, 57-81. https://doi.org/10.1111/j.1541 4337.2009.00094.x

Binder, E. M., Tan, L. M., Chin, L. J., Handl, J., \& Richard, J. (2007) Worldwide occurrence of mycotoxins in commodities, feeds and feed ingredients. Animal feed science and technology,137(3), 265-282. https://doi.org/10.1016/j.anifeedsci.2007.06.005

Blanc, P., Laussac, J. P., Le Bars, J., Le Bars, P., Loret, M. O., Pareilleux, A., ... \& Goma, G. (1995). Characterization of monascidin A from Monascus as citrinin. International journal of food microbiology,27(2-3), 201-213. https://doi.org/10.1016/0168-1605(94)00167-5

Blechova, P., Havlova, P., Gajdošová, D., \& Havel, J. (2006). New possibilities of matrix-assisted laser desorption ionization time of flight mass spectrometry to analyze barley malt quality. Highly sensitive detection of mycotoxins. Environmental toxicology, 21(4), 403-408 https://doi.org/10.1002/tox.20195

Bryden, W.L. (2012). Mycotoxin contamination of the feed supply chain Implications for animal productivity and feed security. Anim. Feed Sci. Technol, 173, 134-158. https://doi.org/10.1016/j.anifeedsci.2011.12.014 
Elosta, S., Gajdošová, D., Hégrová, B., Havel, J. (2007). ORIGINAL ARTICLE MALDI TOF mass spectrometry of selected mycotoxins in barley, J. Appl.

Biomed. 5, 39-47.

Engelhardt, G., Zill, G., Wohner, B., \& Wallnöfer, P. R. (1988). Transformation of the Fusarium mycotoxin zearalenone in maize cell suspension cultures. Naturwissenschaften, 75(6), 309-310. https://doi.org/10.1007/bf00367324

Farzaneh, M., Shi, Z. Q., Ghassempour, A., Sedaghat, N., Ahmadzadeh, M., Mirabolfathy, M., \& Javan-Nikkhah, M. (2012). Aflatoxin B1 degradation by Bacillus subtilis UTBSP1 isolated from pistachio nuts of Iran. Food control, 23(1), 100-106. https://doi.org/10.1016/j.foodcont.2011.06.018

Goryacheva, I. Yu, Saeger, S. De, Nesterenko, I.S., Eremin, S.A., Peteghem, C. Van. (2007). Rapid all-in-one three-step immunoassay for non-instrumenta detection of ochratoxin A in high-coloured herbs and spices, Talanta, 72, 12301234. https://doi.org/10.1016/j.talanta.2006.12.049

Halenar, M., Medvedova, M., Maruniakova, N., \& Kolesarova, A. (2015) Assessment of a potential preventive ability of amygdalin in mycotoxin-induced ovarian toxicity. Journal of Environmental Science and Health, Part B, 50(6), 411-416. https://doi.org/10.1080/03601234.2015.1011956

Chauhan, R., Singh, J., Sachdev, T., Basu, T., Malhotra, B.D. (2016). Biosensors and Bioelectronics Recent advances in mycotoxins detection. Biosens. Bioelectron., 81, 532-545. https://doi.org/10.1016/j.bios.2016.03.004

IARC, IARC. (2015). Monographs on the Evaluation of Carcinogenic Risks to Humans. Available from: http://monographs.iarc.fr/ ENG/Classification

Kolesarova, A., Capcarova, M., Maruniakova, N., Lukac, N., Ciereszko, R. E., \& Sirotkin, A. V. (2012). Resveratrol inhibits reproductive toxicity induced by deoxynivalenol. Journal of Environmental Science and Health, Part A, 47(9), 1329-1334. https://doi.org/10.1080/10934529.2012.672144

Krajl, Cigić, I., Prosen, H. (2009). An Overview of Conventional and Emerging Analytical Methods for the Determination of Mycotoxins, 62-115. https://doi.org/10.3390/ijms10010062

Li, Y., Zhou, Y. C., Yang, M. H., \& Ou-Yang, Z. (2012). Natural occurrence of citrinin in widely consumed traditional Chinese food red yeast rice, medicinal plants and their related products. Food Chemistry, 132(2), 1040-1045. https://doi.org/10.1016/j.foodchem.2011.11.051

Marroquín-Cardona, A. G., Johnson, N.M., Phillips, T.D., Hayes, A. W. (2014). Mycotoxins in a changing global environment - A review. Food Chem. Toxicol., 69, 220-230. https://doi.org/10.1016/j.fct.2014.04.025

Maruniaková, N., Baková, Z., Kádasi, A., Bulla, J., Capcarová, M., \& Kolesárová, A. (2012). Intracellular mechanisms of a-trichothecenes involved in the regulation of cell survival and apoptosis: a review. The Journal of Microbiology, Biotechnology and Food Sciences, 1, 661-670.

Maruniakova, N., Kadasi, A., Sirotkin, A. V., Bulla, J., \& Kolesarova, A. (2014) T-2 toxin and its metabolite HT-2 toxin combined with insulin-like growth factor-I modify progesterone secretion by porcine ovarian granulosa cells. Journal of Environmental Science and Health, Part A, 49(4), 404-409. https://doi.org/10.1080/10934529.2014.854650

Maruniakova, N., Kadasi, A., Sirotkin, A. V., Leśniak, A., Ferreira, A. M., Bulla, J., \& Kolesarova, A. (2015). Assessment of T-2 toxin effect and its metabolite HT-2 toxin combined with insulin-like growth factor I, leptin and ghrelin on progesterone secretion by rabbit ovarian fragments. Journal of Environmental

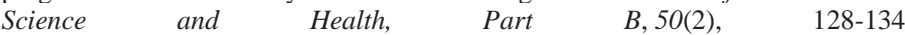
https://doi.org/10.1080/03601234.2015.975622

Medvedova, M., Kolesarova, A., Capcarova, M., Labuda, R., Sirotkin, A. V., Kovacik, J., \& Bulla, J. (2011). The effect of deoxynivalenol on the secretion activity, proliferation and apoptosis of porcine ovarian granulosa cells in vitro. Journal of Environmental Science and Health Part B, 46(3), 213-219. https://doi.org/10.1080/03601234.2011.540205

Oliveira, D.N. De, Catharino, R.R. (2014). Rapid and Simultaneous In Situ Assessment of Aflatoxins and Stilbenes Using Silica Plate Imprinting Mass Spectrometry Imaging. PLos ONE, 9 (3) https://doi.org/10.1371/journal.pone.0090901

Petit, K. E., Mondeguer, F., Roquebert, M. F., Biard, J. F., \& Pouchus, Y. F. (2004). Detection of griseofulvin in a marine strain of Penicillium waksmanii by ion trap mass spectrometry. Journal of microbiological methods, 58(1), 59-65. https://doi.org/10.1016/j.mimet.2004.03.004

Ramos Catharino, R., de Azevedo Marques, L., Silva Santos, L., Baptista, A. S.

Glória, E. M., Calori-Domingues, M. A., ... \& Eberlin, M. N. (2005). Aflatoxin screening by MALDI-TOF mass spectrometry. Analytical chemistry, 77(24), 8155-8157. https://doi.org/10.1021/ac051111p

Rundberget, T., \& Wilkins, A. L. (2002). Determination of Penicillium mycotoxins in foods and feeds using liquid chromatography-mass spectrometry. Journal of Chromatography A,964(1), 189-197. https://doi.org/10.1016/s0021-9673(02)00698-2

Tanaka, K., Waki, H., Ido, Y., Akita, S., Yoshida, Y. (1988). Protein and Polymer Analyses up to mlz 100000 by Laser Ionization Time-of-flight Mass Spectrometry, Rapid comunication in Mass Spectormetry, 2 (8), 151-153 https://doi.org/10.1002/rcm.1290020802

Turner, N.W., Bramhmbhatt, H., Szabo-vezse, M., Poma, A., Coker, R., Piletsky, S.A. (2015). Analytica Chimica Acta Analytical methods for determination of mycotoxins: An update (2009 - 2014). Anal. Chim. Acta, 901, 12-33 https://doi.org/10.1016/j.aca.2015.10.013

Wang, L., Chen, W., Ma, W., Liu, L., Ma, W., Zhao, Y. (2011). Fluorescent strip sensor for rapid determination of toxins, Chem. Commun, 47, 1574-1576 https://doi.org/10.1039/c0cc04032k

Zain, M.E. (2011). Impact of mycotoxins on humans and animals. J. Saudi Chem. Soc. 15, 129-144. https://doi.org/10.1016/j.jscs.2010.06.006 